\title{
Relationship between $\triangle$ SOFA and mortality in patients admitted to the intensive care unit
}

\author{
PC Arvizu-Tachiquín*, JA Baltazar-Torres, AA Cano-Oviedo, A Esquivel-Chávez, S Zamora-Varela, NA Canedo-Castillo \\ From ESICM LIVES 2015 \\ Berlin, Germany. 3-7 October 2015
}

\section{Introduction}

Prognostic scores are important for clinical and administrative management of intensive care units (ICU). SOFA score was designed to describe the sequence of complications during the patient's stay in the ICU, not to predict outcomes. However, it has been shown that high scores on the SOFA score are associated with high mortality. $\triangle$ SOFA is a measure derived from the SOFA score defined as the difference between the SOFA score at admission and the achieved in a determined point of time.

\section{Objectives}

To evaluate the relationship between $\triangle$ SOFA and mortality in patients admitted to the ICU.

\section{Methods}

Adult patients of both sexes with stay in the ICU $>48$ hours were analyzed. Demographic and clinical variables were recorded. The SOFA score was computed on admission and every 48 hours during the stay in the ICU. $\triangle$ SOFA was calculated and evaluated as a predictor of mortality through its discriminative capacity and calibration. Logistic regression analysis was performed to identify independent risk factors of death. A p value $<0.05$ was considered statistically significant. SPSS 20.0 was used for data analysis.

\section{Results}

Eighty patients, mean age 46 years, $53.8 \%$ men were included. The mean length of stay in ICU was 5.11 days and the mortality of $16.3 \%$. The mean SOFA score at admission, maximum and $\triangle$ SOFA were 6.01, 6.27 and 0.26 , respectively. $\triangle$ SOFA showed good discriminative capacity and calibration for predicting mortality (area under the ROC curve $0.914,95 \%$ CI $0.881-1.0, \mathrm{p}<0.05$;
Hosmer-Lemeshow $\mathrm{Chi}^{2}$ 0.371, $\mathrm{p}=0.96$ ) and is a risk factor for death.

\section{Conclusions}

$\triangle$ SOFA is useful in predicting mortality in patients admitted to the ICU.

Published: 1 October 2015

\section{References}

1. Knaus WA, Draper EA, Wagner DP: APACHE II: a severity of disease classification system. Crit Care Med 1985, 13:818-29.

2. Poole D, Rossi C, Anghileri A: External validation of the simplified acute physiology score (SAPS) 3 in a cohort of 28,0357 patients from 147 italian intensive care units. Intensive Care Med 2009, 35:1916.

3. Lemeshow S, Teres D, Klar J: Mortality Probability Models (MPM-II) based on an international cohort of intensive care unit patients. JAMA 1993, 270:2478.

4. Vincent JL, Moreno R, Takala J: The SOFA (sepsis-related organ failure assessment) score to describe organ dysfunction/ failure. Intensive Care Med 1996, 22:707-10

5. Moreno $R$, Vincent $J$, Matos $A$ : The use of maximum SOFA score to quantify organ dysfunction/failure in intensive care: results of a prospective, multicentre study. Intensive Care Med 1999, 25:686-96.

6. Lopes F: Serial evaluation of the SOFA score to predict outcome in critically III patients. JAMA 2001, 286:1754-8.

7. Minne L, Abu-Hanna A, De Jonge E: Evaluation of SOFA-based models for predicting mortality in the ICU: A systematic review. Crit Care Med 2008, 12:1-13.

8. Namendys-Silva SA, Silva-Medina MA, Vasquez-Barahona GM: Application of a modified sequential organ failure assessment score to critically ill patients. Braz J Med Biol Res 2013, 46:186-93.

doi:10.1186/2197-425X-3-S1-A339

Cite this article as: Arvizu-Tachiquín et al:: Relationship between $\triangle$ SOFA and mortality in patients admitted to the intensive care unit. Intensive Care Medicine Experimental 2015 3(Suppl 1):A339. 